\title{
The effect of prostaglandin F-2 $\alpha$ infusion on uterine motility in surgically aborted goats
}

\author{
R. G. Cooke, A. Knifton, R. J. Fitzpatrick* and W. R. Ward* \\ Department of Pharmacology, University of Liverpool, Liverpool, L69 3BX and \\ * Department of Veterinary Clinical Studies, University of Liverpool, Neston, L64 7TE, U.K.
}

In goats the corpus luteum (CL) is essential for the maintenance of pregnancy (Meites, Webster, Young, Thorp \& Hatch, 1951). Cooke, Knifton \& Ward (1975) showed that removal of the CL caused a sudden decline in uterine venous plasma concentrations of progesterone and abortion occurred after a consistent interval of $30 \mathrm{~h}$; there was an abrupt increase in the concentration of uterine venous plasma prostaglandin (PG) $\mathrm{F}$ about $24 \mathrm{~h}$ after removal of the $\mathrm{CL}$, before or coincident with cervical softening and dilatation. The present experiments were designed to examine, on this simplified 'model', any effects of intra-arterial infusions of PGF-2 $\alpha$ on uterine motility, cervical dilatation and the interval to abortion.

Surgery was performed on three goats between 121 and 129 days after mating; anaesthesia was induced with i.v. thiopentone and maintained with halothane and oxygen. A nylon intravenous cannula (Portex Ltd, Hythe, England) was inserted into the uterine vein so that the tip lay approximately $5 \mathrm{~cm}$ from the vena cava; a soft, polyethylene air-filled balloon $(27 \times 5 \mathrm{~mm}$ : Portex Ltd $)$ was inserted between the uterine wall and fetal membranes. Corpora lutea were then removed and $a$. cannula was inserted via the femoral artery into the aorta so that the tip lay anterior to the uterine artery (demonstrated by radiography and subsequently confirmed at autopsy).

In each animal PGF-2 $\alpha$ (Prostin $F_{2 \alpha}$ : Upjohn Ltd, Crawley, England) was infused at a rate of $20 \mu \mathrm{g} / \mathrm{min}$ into the aorta for three 3-h periods beginning $2 \mathrm{~h}$ after removal of $\mathrm{CL}$; each infusion was separated by a 3-h interval. In one of the three goats (G16-see Text-fig. 1), heparinized saline was infused during the intervals between PGF-2 $\alpha$ infusions. Uterine blood samples were withdrawn into heparinized nylon syringes and centrifuged within 10 min of collection. Plasma was stored at $-30^{\circ} \mathrm{C}$ until required for assay. Cannulae were flushed with 2-3 $\mathrm{ml}$ heparinized saline $(50 \mathrm{i} . \mathrm{u} . / \mathrm{ml})$ after each blood collection. In all animals the cervix was palpated after each sample to assess consistency and to detect dilatation. Intrauterine pressure was recorded via polythene tubing connected to a Bell and Howell pressure transducer and a 2-channel recorder (Devices Ltd, Welwyn Garden City, England), a system which has been critically assessed by Jones \& Knifton (1975). All hormones were estimated by specific radioimmunoassays; PGF (i.e. PGF-1 $\alpha$ and PGF-2 $\alpha$ ) according to a modified version of that described by Sharma (1972) and progesterone, oestrone, oestradiol-17 $\alpha$ and oestradiol-17 $\beta$ according to the method of Hotchkiss, Atkinson \& Knobil (1971). The specificities and crossreactions of the antisera used have been reported (Sharma, 1972; Furr, 1973; Dobson \& Dean, 1974); the sensitivity of each assay was $18 \cdot 1 \mathrm{pg}$ for PGF, $4 \cdot 1 \mathrm{pg}$ for progesterone, $6 \cdot 1 \mathrm{pg}$ for oestrone, $9 \cdot 8 \mathrm{pg}$ for oestradiol-17 $\alpha$ and 7.2 pg for oestradiol-17 $\beta$. Results for PGF are presented without correction for recovery which was, in goat plasma, $86 \cdot 1 \pm 6 \cdot 3 \%(n=40)$. Results for all steroids are corrected for recovery which was $69 \cdot 8 \pm 4 \cdot 2 \%(n=30)$ for progesterone; $81.4 \pm 3.5 \%(n=40)$ for oestrone; $82.9 \pm 3.6 \%(n=35)$ for oestradiol-17 $\alpha$ and $82 \cdot 5 \pm 4.2 \%(n=31)$ for oestradiol-17 $\beta$. Data were analysed using Spearman's Rank correlation coefficient and are presented as mean \pm S.D.

Concentrations of PGF and steroids in uterine venous plasma in each goat are summarized in Text-fig. 1. The mean PGF concentration for the 3 goats during infusion was $9.90 \pm 3.86 \mathrm{ng} / \mathrm{ml}$ $(n=35)$ and was significantly greater $(P<0.001)$ than the mean concentration of $1.32 \pm 0.34 \mathrm{ng} / \mathrm{ml}$ $(n=45)$ before and between infusions. There was an abrupt decline in progesterone concentration after removal of the CL and before infusion of PGF-2 $\alpha$ was commenced. In all 3 animals, the first PGF-2 $\alpha$ infusion was given before there was any significant rise $(P<0.05)$ in oestrogen concentrations; these increased between 6 and $14 \mathrm{~h}$ after removal of $\mathrm{CL}(0 \mathrm{~h})$ and preceded the rise in endogenous PGF at abortion. 

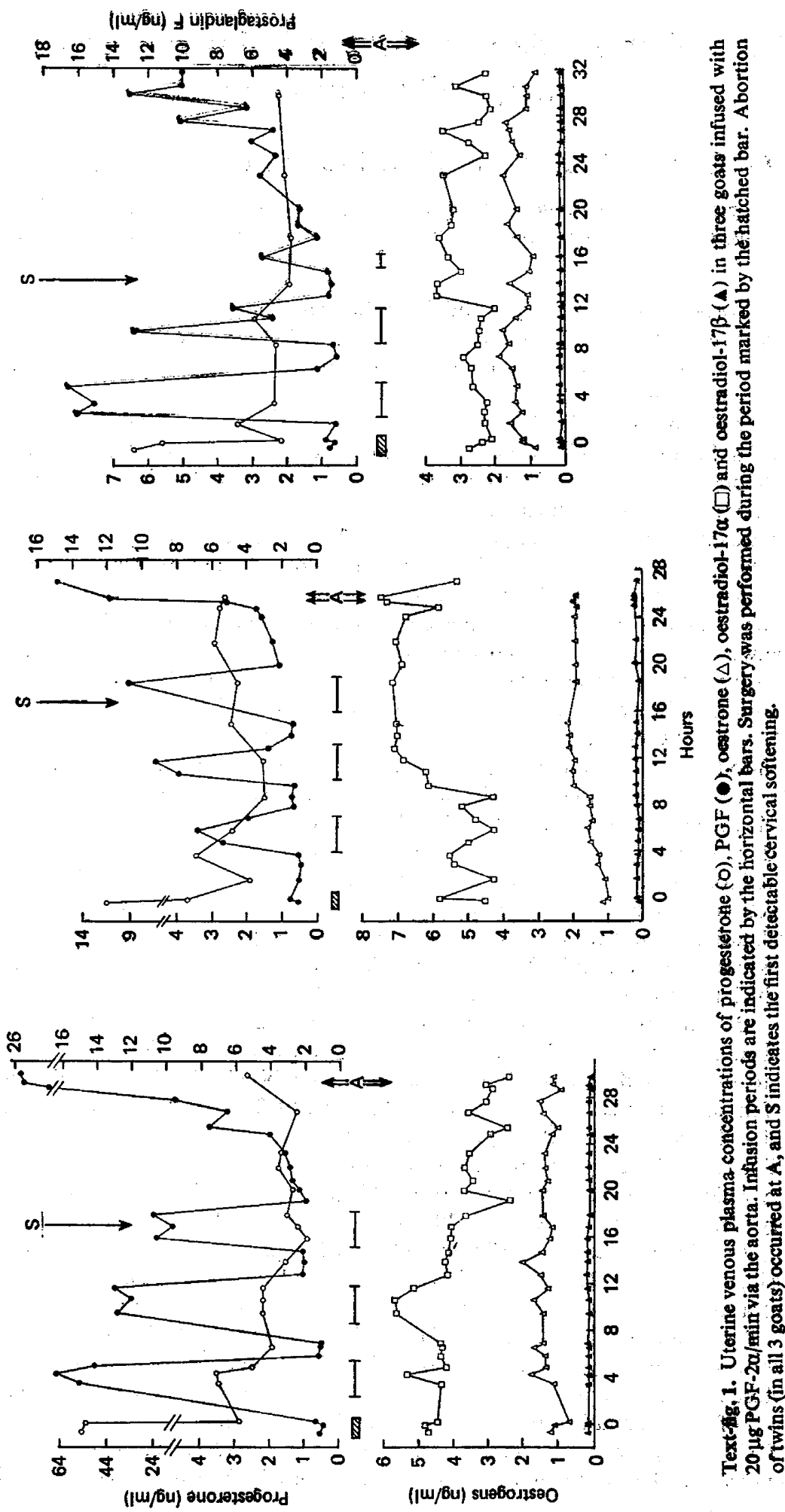
Two typical uterine responses in different animals to the infusion of PGF-2 $\alpha$ are shown in Textfig. 2. After a delay of approximately $3 \mathrm{~min}$, there was initial hypertonus followed by increased amplitude of contractions. The mean uterine activity (Montevideo units, as defined by CaldeyroBarcia et al., 1957) for the total infusion periods showed a threefold increase compared to that between infusions $(P<0.001)$. Control infusions of saline had no effect on uterine motility.

Abortion occurred after a mean interval of $30 \cdot 0 \pm 3 \cdot 2 \mathrm{~h}$ (all fetuses were viable) and this was not significantly different from the time reported previously for aborting goats which did not receive infusions of PGF-2 $\alpha$ (Cooke et al., 1975). The mean interval from removal of CL to a detectable change in the consistency of the cervix was $15.94 \pm 1.75 \mathrm{~h}$, which was significantly less $(P<0.02)$ than the $23.61 \pm 1.62 \mathrm{~h}$ in non-infused goats (Cooke et al., 1975). Flint, Forsling, Mitchell \& Turnbull (1975) reported that vaginal distension for 4 min raised PGF concentrations for about 20 min and increased uterine activity in pregnant sheep. In the present study, vaginal examination took no longer than $10 \mathrm{sec}$. Any possible effects of anaesthesia on the experimental results are difficult to assess. All animals were conscious and able to stand when recording of uterine motility was started. There were fluctuations in plasma hormone concentrations during surgery (Text-fig. 1) but whether this was due to the anaesthesia or surgical manipulation cannot be resolved.

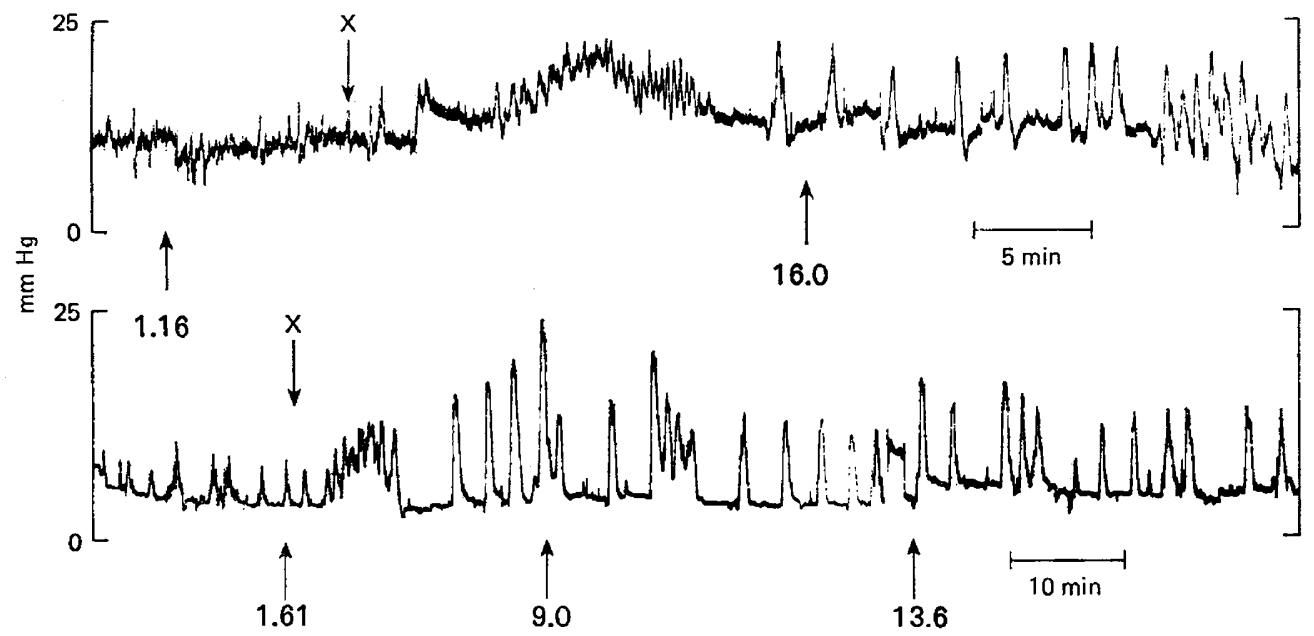

Text-fig. 2. Uterine motility in 2 goats infused with $20 \mu \mathrm{g} \mathrm{PGF-2} \alpha /$ min via the aorta. Infusion started at $X$ and the figures give the uterine venous plasma concentrations of PGF (ng/ml) at the times indicated.

The dramatic increase in the concentration of PGF just before abortion is similar to that previously described for goats at normal parturition (Thorburn, Nicol, Bassett, Shutt \& Cox, 1972; Umo, Fitzpatrick \& Ward, 1976) and it could produce several effects. In the present study, infusion of physiological concentrations of PGF-2 $\alpha$, after removal of the CL and before release of endogenous PGF into the uterine vein at abortion, increased uterine contractility. Mitchell, Flint \& Turnbull (1976) reported similar acute effects of PGF-2 $\alpha$ on uterine motility during induced parturition in sheep, and they suggested that the effect may have been missed by previous investigators because too low a dose was given. However, the uterine venous plasma concentrations of PGF which Mitchell et al. (1976) attained by infusion were more than twice those found in the present study in goats. Secondly, myometrial sensitivity to oxytocin in sheep is greatly increased by infusions of PGF (Liggins, Fairclough, Grieves, Kendall \& Knox, 1973). A similar mechanism might operate in the goat at normal parturition when oxytocin is also released (Irving, Jones \& Knifton, 1971; McNeilly, Martin, Chard \& Hart, 1972). Thirdly, infusion of PGF-2 $\alpha$ shortened the time from removal of CL to softening of the cervix; this might be an indirect effect due to the increased uterine contractility produced by PGF-2 $\alpha$, but there may also be a direct action of prostaglandins on the cervix (Fitzpatrick, 1977). 
We wish to thank I.C.I. Ltd for a grant in support of this work, Mr C. West for advice on statist ical analysis and Mrs P. Fawcett for technical assistance.

\section{References}

Caldeyro-Barcia, R., Sica-Blanco, Y., Poseiro, J.J., Gonzalez-Panizza, V., Mendez-Bauer, C., Fielitz, C., Alvarez, H., Pose, S.V. \& Hendricks, C.H., (1957) A quantitative study of the action of synthetic oxytocin on the pregnant human uterus. J. Pharmac. exp. Ther. 121, 18-31.

COOKE, R.G., KNIFToN, A. \& WARD, W.R. (1975) Prostaglandin F and progesterone plasma levels in surgically aborted goats. Int. Res. Commun. Syst., Med. Sci. 3, 628.

Dobson, H. \& DEAN, P.D.G. (1974) Radioimmunoassay of oestrone, oestradiol-17 $\alpha$ and oestradiol-17 $\beta$ in bovine plasma during the oestrous cycle and last stages of pregnancy. $J$. Endocr. 61, 479-486.

FITZPATRICK, R.J. (1977) Dilatation of the uterine cervix. In The Fetus and Birth, pp. 31-47. Ed. J. Knight. Associated Scientific Publishers, Amsterdam.

Flint, A.P.F., Forsling, M.L., Mrtchell, M.D. \& TuRnbull, A.C. (1975) Temporal relationship between changes in oxytocin and prostaglandin $F$ levels in response to vaginal distension in the pregnant and puerperal ewe. J. Reprod. Fert. 43, 551-554.

FURR, B.J.A. (1973) Radioimmunoassay of progesterone in peripheral plasma of domestic fowl and in follicular venous plasma. Acta endocr., Copenh. 72, 89-100.

Hotchkiss, J., Atkinson, L.E. \& KNobil, E. (1971) Time course of serum oestrogens and $\mathrm{LH}$ concentrations during the menstrual cycle of rhesus monkeys. Endocrinology 89, 177-183.

Irving, G., Jones, D.E. \& KNIFToN, A. (1971) Milkejection activity in goat plasma during parturition. Res. vet. Sci. 12, 472-474.
JoNEs, D.E. \& KNIFTon, A. (1975) Effects of female sex hormones on uterine motility and reactivity to oxytocin in goats. Res. vet. Sci. 18, 288-293.

Liggins, G.C., Fairclough, R.J., Grieves, S.A., KendALL, J.Z. \& KNOX, B.S. (1973) The mechanism of initiation of parturition in the ewe. Recent Prog. Horm. Res. 29, 111-159.

McNeilly, A.S., Martin, M.J., Chard, T. \& Hart I. (1972) Simultaneous release of oxytocin and neurophysin during parturition in the goat. $J$. Endocr. 52, 213-214.

Meites, J., Webster, H.D., Young, F.W., ThoRp, F., \& HATch, R.N. (1951) Effects of corpora lutea removal and replacement with progesterone on pregnancy in goats. J. Anim. Sci. 10, 411-416.

Mitchell, M.D., Flint, A.P.F. \& TuRnbull, A.C. (1976) Stimulation of uterine activity by administration of prostaglandin $F-2 \alpha$ during parturition in sheep. J. Reprod. Fert. 48, 189-190.

ShaRMA, S.C. (1972) A sensitive radioimmunoassay for prostaglandin F. J. Physiol., Lond. 226, 64P.

Thorburn, G.D., Nicol, D.H., Bassett, J.M., ShuTt, D.A. \& Cox, R.I. (1972) Parturition in the goat and sheep: changes in corticosteroids, progesterone, oestrogens and prostaglandin F. J. Reprod. Fert., Suppl. 16, 61-84.

UMo, I., FITzPatrick, R.J. \& WaRD, W.R. (1976) Parturition in the goat: plasma concentrations of prostaglandin $\mathrm{F}$ and steroid hormones and uterine activity during late pregnancy and parturition. $J$. Endocr. 68, 383-389.

Received 8 December 1976 